\title{
A Tungsten-Based Nanolaminated Ternary Carbide: (W,Ti)(4)C4-x
}

Babak Anasori, J un Lu, Oleg Rivin, Martin Dahlqvist, J oseph Halim, Cooper Voigt, J ohanna Rosén, Lars Hultman, Michel W. Barsoum and Elad N. Caspi

The self-archived postprint version of this journal article is available at Linköping University Institutional Repository (DiVA):

http:// urn.kb.se/ resolve?urn=urn:nbn:se:liu:diva-154693

N.B.: When citing this work, cite the original publication.

Anasori, B., Lu, J., Rivin, O., Dahlqvist, M., Halim, J., Voigt, C., Rosén, J ., Hultman, L., Barsoum, M. W., Caspi, E. N., (2019), A Tungsten-Based Nanolaminated Ternary Carbide: (W,Ti)(4)C4-x, Inorganic Chemistry, 58(2), 1100-1106. https:// doi.org/ 10.1021/ acs.inorgchem.8b02226

Original publication available at:

https:// doi.org/ 10.1021/acs.inorgchem.8b02226

Copyright: American Chemical Society

http:// pubs.acs.org/ 


\title{
A Tungsten-Based Nanolaminated Ternary Carbide: $(\mathrm{W}, \mathbf{T i})_{4} \mathrm{C}_{4-\mathrm{x}}$
}

\author{
Babak Anasori, ${ }^{1,2, *}$ Jun Lu, ${ }^{3, *}$ Oleg Rivin, ${ }^{4}$ Martin Dahlqvist, ${ }^{3}$ Joseph Halim, ${ }^{3}$ Cooper Voigt, ${ }^{1}$ Johanna \\ Rosen, ${ }^{3}$ Lars Hultman, ${ }^{3}$ Michel W. Barsoum, ${ }^{1, *}$ El'ad N. Caspi, ${ }^{1,4}$ \\ ${ }^{1}$ Department of Materials Science \& Engineering, Drexel University, Philadelphia, PA 19104, USA \\ ${ }^{2}$ A. J. Drexel Nanomaterials Institute, Drexel University, Philadelphia, PA 19104, USA \\ ${ }^{3}$ Thin Film Physics Division, Department of Physics, Chemistry and Biology (IFM), Linköping University, SE- \\ 58183 Linköping, Sweden \\ ${ }^{4}$ Physics Department, Nuclear Research Centre - Negev, 84190 Beer-Sheva, Israel \\ ${ }^{*}$ Corresponding authors: \\ anasori@drexel.edu (B. Anasori) \\ Jun.lu@liu.se (J. Lu) \\ barsoumw@drexel.edu (M.W. Barsoum)
}

KEYWORDS: Nanolamellar transition metal carbides, non-stoichiometric carbides, Z-contrast STEM, MAX phases

\begin{abstract}
Nanolamellar transition metal carbides are gaining increasing interests because of the recent developments of their two-dimensional (2D) derivatives and promising performance for a variety of applications from energy storage, catalysis to transparent conductive coatings, and medicine. To develop more novel 2D materials, new nanolaminated structures are needed. Here we report on a tungstenbased nanolaminated ternary phase, $(\mathrm{W}, \mathrm{Ti})_{4} \mathrm{C}_{4-\mathrm{x}}$, synthesized by an Al-catalyzed reaction of $\mathrm{W}, \mathrm{Ti}$, and $\mathrm{C}$ powders at $1600{ }^{\circ} \mathrm{C}$ for $4 \mathrm{~h}$, under flowing argon. X-ray and neutron diffraction, along with Z-contrast scanning transmission electron microscopy, were used to determine the atomic structure, ordering, and occupancies. This phase has a layered hexagonal structure $\left(\mathrm{P}_{3} / \mathrm{mmc}\right)$ with lattice parameters, $\mathrm{a}=3.00880(7) \AA$, and $\mathrm{c}=19.5633(6) \AA$ and a nominal chemistry of $(\mathrm{W}, \mathrm{Ti})_{4} \mathrm{C}_{4-\mathrm{x}}$ (actual chemistry, $\mathrm{W}_{2.1(1)} \mathrm{Ti}_{1.6(1)} \mathrm{C}_{2.6(1)}$ ). The structure is comprised of layers of pure $\mathrm{W}$ that are also twin planes with two adjacent atomic layers of mixed $\mathrm{W}$ and $\mathrm{Ti}$, on either side. The use of $\mathrm{Al}$ as a catalyst for synthesizing otherwise difficult to make phases, could in turn lead to the discovery of a large family of nonstoichiometric ternary transition metal carbides, synthesized at relatively low temperatures and shorter times.
\end{abstract}




\section{INTRODUCTION}

Group IV to VI transition metal carbides (TMCs) and nitrides (TMNs) are sometimes referred to as metallic ceramics, because they combine high metallic conductivities with ceramic properties such as chemical stability, high hardness, and high melting points. Some are used as cutting tools, wear-resistant, and high-temperature materials. ${ }^{1}$ Several nanostructure designs of this family of materials have been explored after their superior catalytic behavior was demonstrated. ${ }^{2,3}$ Additionally, group III to VI transition metals form ternary nanolaminated structures by combining with A-group elements. The Mn+1AXn or MAX phases (where M is an early transition metal, A is an A-group element, mostly groups 13 and 14 of the periodic table, and $\mathrm{X}$ is $\mathrm{C}$ and/or $\mathrm{N}$ with $\mathrm{n}=1$ to 3 ) are one such example. The first MAX phase, $\mathrm{Cr}_{2} \mathrm{AlC}$, was reported by Bloom and Grant in 1950, and labeled an H-phase. ${ }^{4}$ In 1960, Kudielka and Rohde discovered a second phase, $\mathrm{Ti}_{2} \mathrm{SC}^{5}$ In the 1960 s, Nowotny et al. discovered over 50 such compounds. ${ }^{6}$ Barsoum et al., however, were the first to make predominantly single phase bulk MAX phase materials and document their unusual set of properties, including machinability. ${ }^{7}$ The MAX phases are hexagonal (space group P63/mmc) with two formula units per unit cell, in which close-packed $\mathrm{M}$ atoms, with interstitial $\mathrm{X}$ atoms in the octahedral sites, are interleaved with pure A-layers. Non-MAX phase ternary structures are known as well. ${ }^{8,9}$

The discovery in 2011 that Al-containing MAX phases could be readily converted to their 2D counterparts, labeled MXenes, by simply immersing in fluoride containing acidic solutions for a few hours at ambient temperature, has given the MAX field, especially Al-containing ones, a large boost in terms of interest and potential applications, not as MAX phases per se, but as precursors to MXenes. ${ }^{10,11} \mathrm{~A}$ more in depth discussion on MXenes is presented in the Supporting Information. Examples of recently discovered MAX phases include quaternaries with two M elements that are either ordered out-of-plane ${ }^{12-16}$ or in-plane, ${ }^{17-19}$ ternary phases with double A layers, ${ }^{20,21}$ or A-element layers substituted with noble transition metals. ${ }^{22}$ Despite several theoretical predictions of W-containing MAX phases, only two W-containing MAX phases have been discovered to date: the in-plane ordered $\left(\mathrm{W}_{2 / 3} \mathrm{Sc}_{1 / 3}\right)_{2} \mathrm{AlC}$ and $\left(\mathrm{W}_{2 / 3} \mathrm{Y}_{1 / 3}\right)_{2} \mathrm{AlC}$ phases. ${ }^{19}$ The dearth of compounds combining $\mathrm{W}$ and $\mathrm{Ti}$ is not only limited to the MAX phases. There are only few studies on TMCs comprised of W and Ti. The first carbide containing Ti and W, was reported in the late of 1930s, but without detailed structure information. ${ }^{23}$ A cubic $(\mathrm{Ti}, \mathrm{W}) \mathrm{C}$ with rock salt structure was first reported by Nowotny et al. in $1954 .{ }^{24}$ Rock salt solid solutions of $\left(\mathrm{Ti}_{1-\mathrm{x}}, \mathrm{W}_{\mathrm{x}}\right) \mathrm{C}$ with different $\mathrm{W}$ contents were also synthesized by hot pressing TiC and WC mixtures at $\sim 2600{ }^{\circ} \mathrm{C} .{ }^{25}$ In another study, cubic single crystals of $\left(\mathrm{Ti}_{1-\mathrm{x}}, \mathrm{W}_{\mathrm{x}}\right) \mathrm{C}$ were grown from an $\mathrm{Al}$ melt at $1600^{\circ} \mathrm{C}$, in which only $20 \mathrm{~mol} \%$ of WC was accommodated in the (Ti,W) C crystals. ${ }^{26}$ Crucially, no hexagonal ordered layered structures of $\mathrm{W}, \mathrm{Ti}$ and $\mathrm{C}$ has been reported to date. ${ }^{27-29}$ Here, we report on the first hexagonal close packed (hcp) W-containing ternary phase with a $\mathrm{M}_{4} \mathrm{C}_{4-\mathrm{x}}$ chemistry starting with a W/Ti/Al/C powder mixture. The original intent was to produce an 
out-of-plane ordered MAX phase. Somewhat surprisingly, the resulting phase with a nominal chemistry of (W,Ti) ${ }_{4} \mathrm{C}_{4-\mathrm{x}}$ and actual chemistry of $\mathrm{W}_{2.1(1)} \mathrm{Ti}_{1.6(1)} \mathrm{C}_{2.6(1)}$ was $\mathrm{Al}$ free. This phase is layered, ordered, and quite different from the structure of either hexagonal WC, ${ }^{30}$ or cubic TiC. ${ }^{31}$ The resulting powder was characterized using a scanning electron microscope (SEM), X-ray diffraction (XRD), selected electron diffraction (SAED), energy dispersive spectrum (EDX), high-resolution scanning transmission electron microscope (HRSTEM), and neutron powder diffraction (NPD).

\section{EXPERIMENTAL DETAILS}

The sample was prepared by ball milling elemental powders of W, Ti, Al, C (all from Alfa Aesar) with particle sizes $<44 \mu \mathrm{m}$ for $24 \mathrm{~h}$ using zirconia balls in plastic jars. The starting W/Ti/Al/C molar ratio was 2:1:1.1:2. The powder mixture was heated in an alumina, $\mathrm{Al}_{2} \mathrm{O}_{3}$, crucible at $5{ }^{\circ} \mathrm{C} / \mathrm{min}$ to $1600{ }^{\circ} \mathrm{C}$ and held for $4 \mathrm{~h}$ under flowing argon. After furnace cooling, the resulting sintered preform was porous enough that we were able to crush it by hand in a mortar and pestle. We then sieved the powder through a 400 mesh sieve producing a powder with a particle size $<37 \mu \mathrm{m}$. These powders ultimately used for XRD and NPD were then soaked in hydrofluoric acid (HF) to dissolve unwanted intermetallic impurities, such as $\mathrm{WAl}_{4}$, to improve the quality of our refinements. To do so, $2 \mathrm{~g}$ of the powder was added to $20 \mathrm{~mL}$ of $48-51 \%$ aqueous HF (Fisher Scientific) and held for $80 \mathrm{~h}$ at $40{ }^{\circ} \mathrm{C}$. The powder was then washed a few times with distilled water, shaken for $1 \mathrm{~min}$, centrifuged at $3500 \mathrm{rpm}$ for $2 \mathrm{~min}$ for each cycle, until the $\mathrm{pH}$ of the supernatant was $>6$. Lastly, the sediment after the last centrifuging step was collected and dried under vacuum at room temperature.

It is worth noting that the initial goal of using $\mathrm{HF}$ was to etch out the $\mathrm{Al}$ from the powder to form 2D tungsten titanium carbide, assuming $\mathrm{Al}$ was in the structure. However, after dissolving the $\mathrm{Al}$ in $\mathrm{HF}$, we found out the structure did not change and further characterization (see below) showed that $\mathrm{Al}$ only acts as a catalyst for the reaction and is not in the crystal structure. To further test this idea, we mixed W/Ti/C powders with no $\mathrm{Al}$ in the stoichiometric ratio of 2:1:2 and followed the same procedure outlined above. In this case, the resulting material crystallized in a mixture of $\mathrm{TiC}_{\mathrm{x}}$ and $\mathrm{W}_{2} \mathrm{C}$ (Supporting Information, Figure S1).

A SEM (Supra50, Zeiss) equipped with an EDX spectroscope (EDX, Oxford Inca X-Sight) was used to qualitatively characterize the powder morphology and its purity. To improve the quality of the backscattered electron SEM micrographs, the powders were cold pressed into a disk at a load corresponding to a stress of $100 \mathrm{MPa}$. To determine the composition of individual grains, we performed EDX on individual grains by zooming on a single particle (magnifications of 50 to $100 \mathrm{k} \times$ ) and ran EDX scans for $\sim 7 \mathrm{~s}$.

XRD was carried out on a Rigaku SmartLab (Japan) diffractometer using step scans of $\Delta 2 \theta=0.02^{\circ}$ in the $2 \theta$ range of $5-120^{\circ}$, and a dwell time of 7 s per step. A $\mathrm{Cu} \mathrm{K \alpha}$ source was used with voltage and current of $40 \mathrm{kV}$ and $44 \mathrm{~mA}$, respectively. The accuracy of the diffractometer in determining lattice parameters, and 
its instrumental peak-shape function parameters were found using $\mathrm{LaB}_{6}$ (NIST 660B) standards resulting in a systematic shift in lattice parameters determination of $\sim-0.06 \%$.

The NPD measurement was performed at room temperature, RT, $(\sim 300 \mathrm{~K})$ at the KANDI-II powder double-axis diffractometer in the Israel Research Reactor No. 2 (IRR-2) at the Nuclear Research Centre, Negev, Israel (Israel Atomic Energy Commission). The diffractometer and its 10 3He-based neutron multidetector, were calibrated using various standard samples (e.g., $\mathrm{Si}, \mathrm{Al}_{2} \mathrm{O}_{3}$ ). The incident neutron beam $[\lambda=2.47(1)]$ was obtained from the (002) reflection of a pyrolytic graphite monochromator. A $\sim$ g sample was loaded into vanadium, $\mathrm{V}$, cylindrical sample holder with a $10 \mathrm{~mm}$ diameter and $\sim 0.2 \mathrm{~mm}$ wall thickness. Both the NPD and XRD diffraction patterns were analyzed by the Rietveld analysis32 method using the FULLPROF code. ${ }^{33}$

HRSTEM and EDX were also carried out with a double-corrected FEI Titan3 60-300 operated at 300 $\mathrm{kV}$, equipped with the Super-X EDX system. SAED characterization was performed using a FEI Tecnai G2 TF20 UT instrument equipped with a field emission gun that runs at a voltage of $200 \mathrm{kV}$ and a point resolution of $0.19 \mathrm{~nm}$. The specimens were prepared by embedding the powder in a Ti grid, reducing the Ti-grid thickness down to $50 \mu \mathrm{m}$ via mechanical polishing and finally $\mathrm{Ar}+$ ion milling to reach electron transparency.

\section{RESULTS AND DISCUSSION}

Before detailing our results, it is important to point out the main finding of this study. As discussed above, the original intent was to make an out-of-plane ordered, W-containing MAX phase, viz. ( $\mathrm{W}_{2} \mathrm{Ti}_{\text {) }} \mathrm{AlC}_{2}$. Instead, we formed a nanolamellar hcp structure of $(\mathrm{W}, \mathrm{Ti})_{4} \mathrm{C}_{4-\mathrm{x}}(\mathrm{x} \approx 1.4)$ that does not include $\mathrm{Al}$. Paradoxically, this phase cannot be synthesized without the presence of $\mathrm{Al}$ in the initial powder mixture, strongly suggesting that $\mathrm{Al}$ is a required catalyst to nucleate this phase. The resulting nanolamellar structure contains two nanotwins that coincide with pure $\mathrm{W}$ planes.

Figures $1 \mathrm{a}-\mathrm{c}$ show SEM images of the as-synthesized $(\mathrm{W}, \mathrm{Ti})_{4} \mathrm{C}_{4-\mathrm{x}}$ powder. The majority of the grains are flaky with a layered morphology. EDX measurement on these grains showed the presence of only W, $\mathrm{Ti}$, and C. Some grains with different morphologies were shown by EDX analysis to be impurities such as $\mathrm{Al}_{2} \mathrm{O}_{3}$ and $\mathrm{WAl}_{4}$. Higher-magnification SEM images in Figures 1b,c again show the layered structure as well as kinked grains (arrows in Figure 1c), which is the characteristic of several hcp crystals with lattice parameters (c/a) ratio of $>1.4 .{ }^{34}$ Backscattered electron SEM micrographs with EDX taken on the pressed discs (Figure 1d) showed the presence of three distinct regions; a majority of W, Ti, C phase (bright gray; labeled A) where EDX showed a W/Ti atomic ratio of 2:1.1(1), and impurity phases, $\mathrm{WAl}_{4}$ (dark gray; B) and $\mathrm{Al}_{2} \mathrm{O}_{3}$ (black; labeled C). 

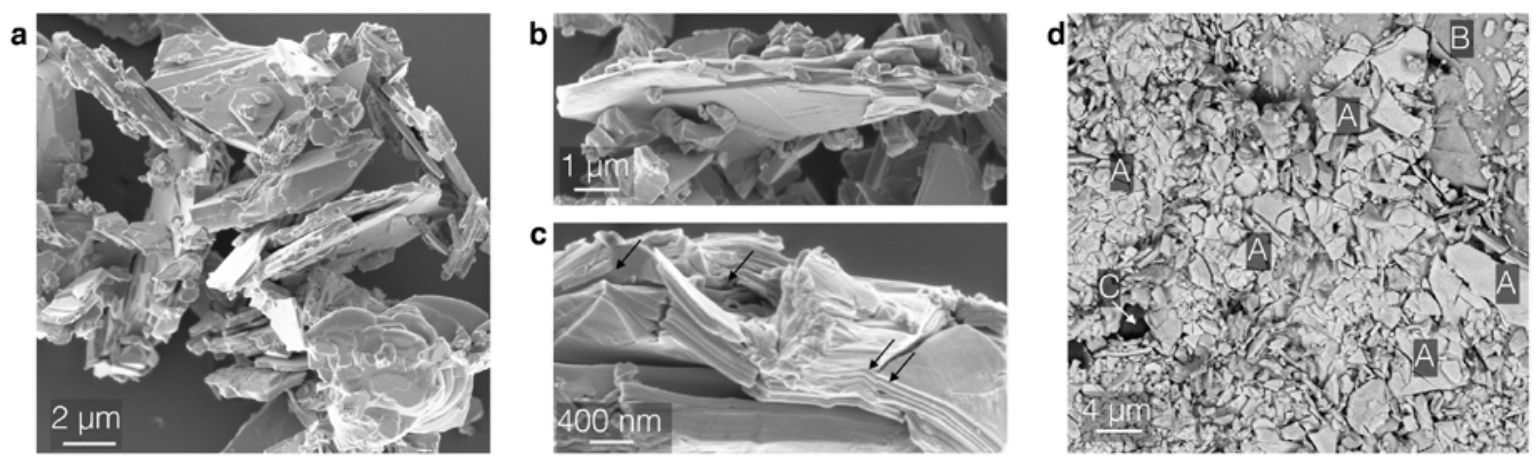

Figure 1| SEM of as synthesized $(\mathrm{W}, \mathrm{Ti})_{4} \mathrm{C}_{4-x}$ powder. $(\mathrm{a}-\mathrm{c})$ Secondary electron SEM micrographs showing elongated, plate-like grains with similar morphologies to the nanolayered structure of the MAX phases. Few grains with different morphology at the bottom of (a) are impurities. (b,c) Higher-magnification images of platelike grains again show the layered structure. Kinks are marked by arrows in (c) and shown in inset. (d) Backscattered electron SEM on a pressed pellet of as-synthesized powder showing at least three regions. The majority of the grains, some of which are labeled $\mathrm{A}$, are bright gray and flaky. EDX of these grains showed only the presence of $\mathrm{W}, \mathrm{Ti}$, and $\mathrm{C}$ with a W/Ti atomic ratio of 2:1.1 \pm 0.1 . The dark gray grains (labeled B) are most probably WAl $\mathrm{WA}_{4}$ and the black grains (labeled C) $\operatorname{are~} \mathrm{Al}_{2} \mathrm{O}_{3}$. The latter two are impurities found in the as-synthesized powder.

The SAED on the as-synthesized powder (Figure 2a,b) can be indexed with a $\mathrm{P}_{3} / \mathrm{mmc}$ hexagonal structure. EDX compositional analysis in the HRTEM on different spots revealed that this compound is indeed $\mathrm{Al}$ free at the precision level of our EDX instrument (Figure 2c). The preliminary atomic coordinates of $\mathrm{W}$ and Ti were obtained from analytical HRSTEM. The Z-contrast images along the [1120] and [1010] zone axes shown in Figure 2d,e, respectively, clearly show bright and gray spots, arranged in separate layers. Since there is no $\mathrm{Al}$, and $\mathrm{C}$ is too light to be visible in such images, we only discuss the positions of the $\mathrm{W}$ and $\mathrm{Ti}$ atoms. Three bright atomic layers and one gray layer are clearly seen, suggesting a $\mathrm{W}$-rich/Ti-rich ordered layered structure. A more detailed intensity profile (inset in Figure 2d,e) clearly demonstrates that the middle bright layer has stronger scattering than the adjacent two less bright layers, indicating either variations in the $\mathrm{W} / \mathrm{Ti}$ relative occupancy or the existence of vacancies in the different layers.

Inspection of the local composition viewed along the [1120] direction reveals partitioning of W (red) and $\mathrm{Ti}$ (green) with three $\mathrm{W}$-rich layers and one Ti-rich layer (see Figure $2 \mathrm{f}-\mathrm{h}$ ). Moreover, the EDX line scan along the [0001] direction (Figure $2 \mathrm{~h}$ ) shows a strong Ti signal along the gray layer together with a weak W signal, suggesting the presence of a Ti rich layer. The brightest layers appear to be comprised of $\mathrm{W}$ alone. The other two adjacent layers show a strong secondary W signal together with weaker Ti peaks. These observations agree with the HRSTEM intensity profile (inset in Figure 2d,e) and support a partially ordered solid solution nanolayered structure that can be expressed as $\left(\mathrm{Ti}_{1-\mathrm{z}} \mathrm{W}_{\mathrm{z}}\right)\left(\mathrm{W}_{1-\mathrm{w}} \mathrm{Ti}_{\mathrm{w}}\right) \mathrm{W}$ $\left(\mathrm{W}_{1-\mathrm{w}} \mathrm{Ti}_{\mathrm{w}}\right)\left(\mathrm{Ti}_{1-\mathrm{z}} \mathrm{W}_{\mathrm{z}}\right)\left(\mathrm{W}_{1-\mathrm{w}} \mathrm{Ti}_{\mathrm{w}}\right) \mathrm{W}\left(\mathrm{W}_{1-\mathrm{w}} \mathrm{Ti}_{\mathrm{w}}\right)$. Note that throughout this paper, the Ti atoms are colored green, the $\mathrm{W}$ atoms, red. 

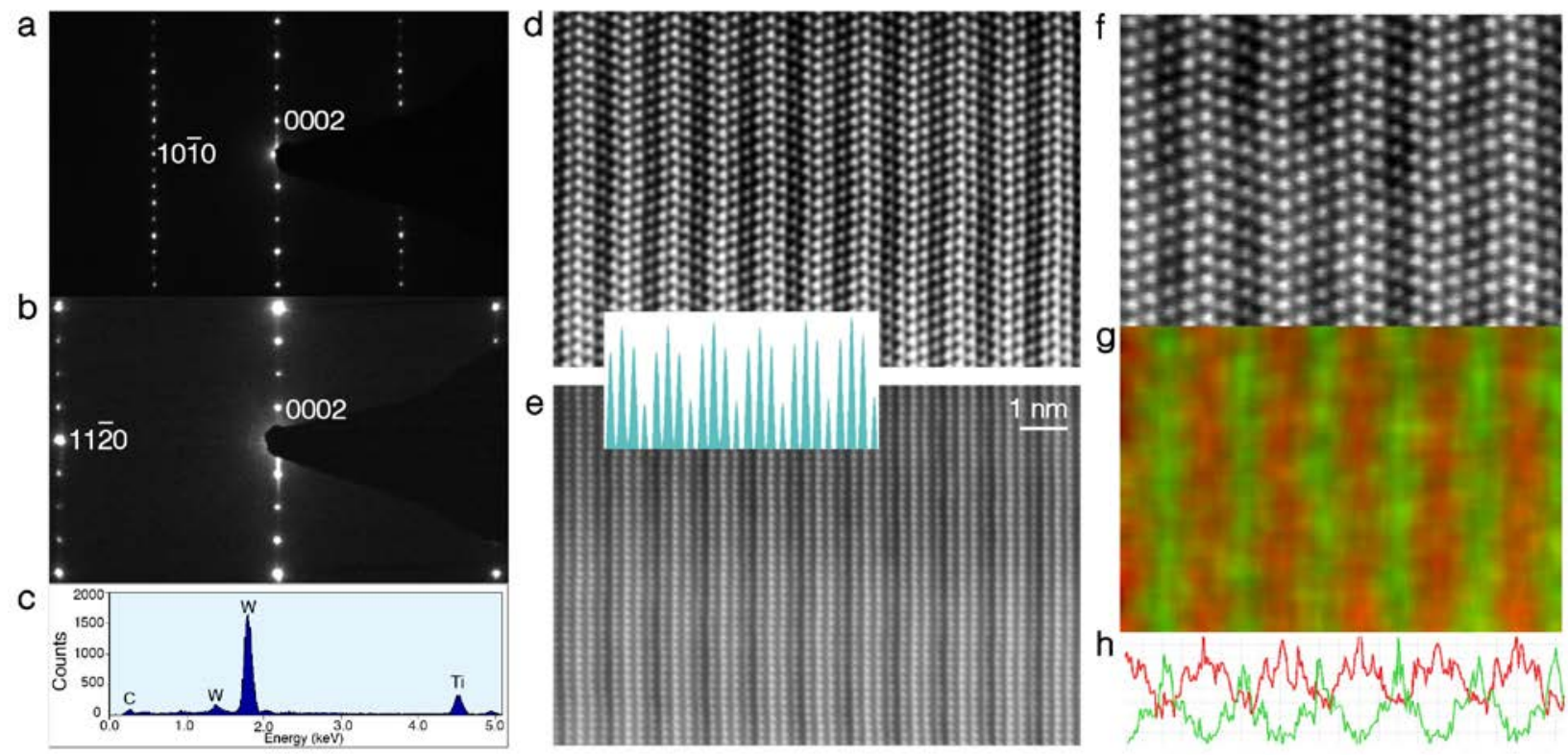

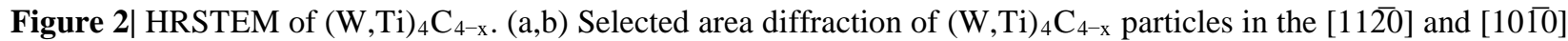
zone axes. (c) Energy dispersive X-ray spectroscopy (EDX) of particles whose SAED are shown in (a,b). (d,e) HRSTEM images of a (W,Ti) ${ }_{4} \mathrm{C}_{4-\mathrm{x}}$ grain along, (d) [1120] and, (e) [1010] zone axes. Inset shows the intensity profile along [0001] direction. (f, g) HRSTEM images of a (W,Ti) ${ }_{4} \mathrm{C}_{4-\mathrm{x}}$ grain along the [1120] with EDX map where W (red) and Ti (green) are shown. (h) EDX profile along [0001] direction, with the same color coding.

The enlarged Z-contrast image along the [1120] zone axis (Figure 3a) illustrates the stacking sequence and the atomic positions of the M elements, in which three different contrasts are apparent. Position $2 \mathrm{~d}$ at $\mathrm{z}$ $=0.75$ (brightest layer, labeled $\mathrm{h}$ in Figure $3 \mathrm{~b}$ ) is occupied by $\mathrm{W}$ only. Position 2a at $\mathrm{z}=0$, gray layer, is occupied mainly by $\mathrm{Ti}$ with some $\mathrm{W}$ referred to as $(\mathrm{Ti}, \mathrm{W})$ in Figure 3b. The two adjacent $(\mathrm{W}, \mathrm{Ti})$ layers, described by the $4 \mathrm{f}$ positions, with a $\mathrm{z}$ along the c-axis of $\sim 0.125$, are referred to as (W,Ti) in Figure $3 \mathrm{~b}$.

If one ignores the $\mathrm{C}$ atoms, then the atomic arrangement, shown by capital letters on left of Figure $3 \mathrm{~b}$, is СВАВСАВАСВАВ $\cdots$, where the underlined layers are pure $\mathrm{W}$. In other words, the $\mathrm{W}$-only planes are twin mirror planes. In that respect, they are similar to the A-layers in the MAX phases. It is easier to understand the atomic ordering by using the Wycoff-Jagodzinski notation, also known as the ch-notation. ${ }^{35,36}$ In this notation, a close-packed plane is marked as h, if its two adjacent planes are symmetrically located relatively to it, similar to a hcp structure (ABABAB). However, if the adjacent planes are nonsymmetrically located relative to the given atomic plane, the plane is marked by c, similar to a cubic close-packed (ABCABC). The (W,Ti) ${ }_{4} \mathrm{C}_{4-\mathrm{x}}$ unit cell can thus be best succinctly described as hc3 (cchccchcc) as shown in blue letters on right of Figure $3 \mathrm{~b}$. Although hc 3 ordering was predicted before, ${ }^{35,36}$ to our knowledge, it has previously never been experimentally observed. In our HRSTEM microscopy, we also observed a stacking fault (Figure S2a), where a Ti-rich layer is replaced with a W-rich layer (see colored arrows in Figure S2b). 

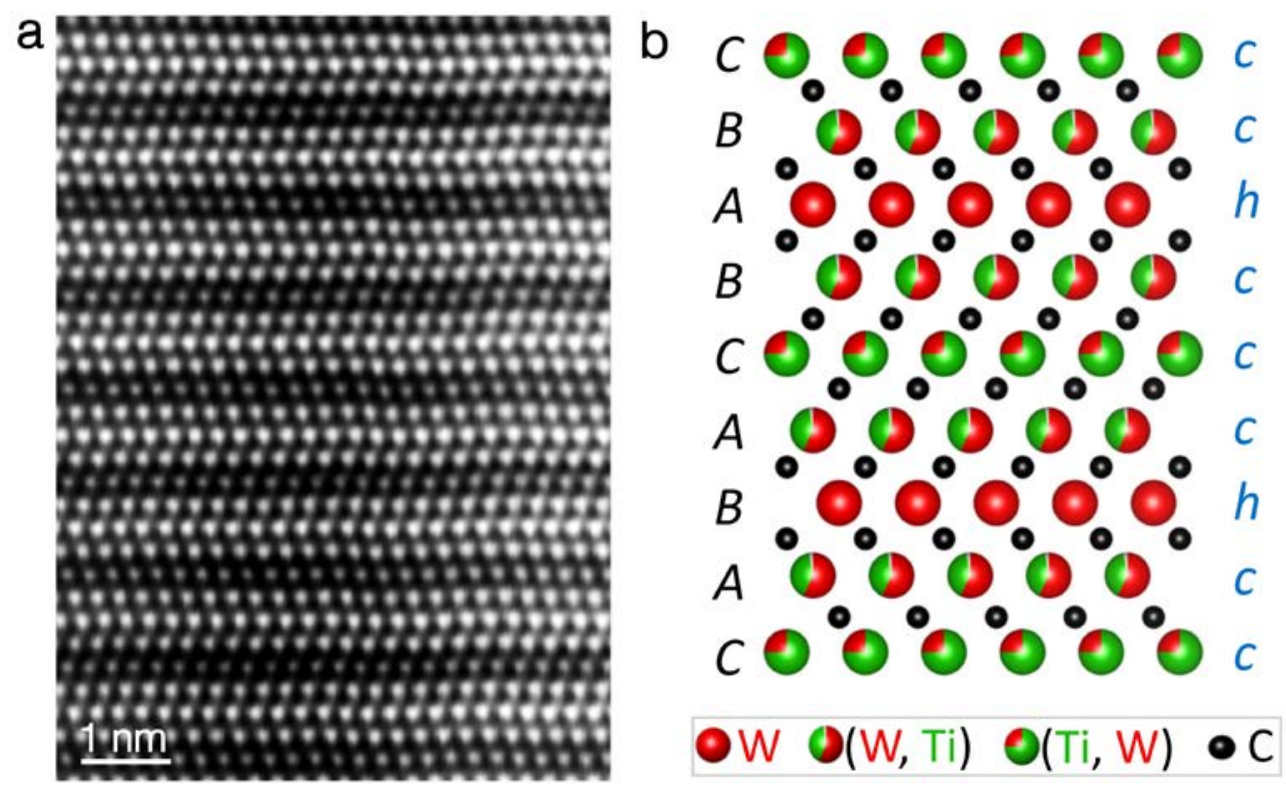

Figure 3| Atomic ordering of $(\mathrm{W}, \mathrm{Ti})_{4} \mathrm{C}_{4-\mathrm{x}}$. (a) HRSTEM image viewed along the [1120] direction, showing atomic planes with different contrast. The brightest layer is $\mathrm{W}$, the two adjacent layers are $\mathrm{W}$-rich (W,Ti) layers. The gray layers with lowest brightness are Ti-rich or (Ti,W) layers. (b) Structure model and stacking sequence of $(\mathrm{W}, \mathrm{Ti})_{4} \mathrm{C}_{4-\mathrm{x}}$, where $\mathrm{W}, \mathrm{Ti}$, and $\mathrm{C}$ are shown by red, green, and black spheres, respectively. The ABC stacking notation is shown in black, on the left side of the structure and the Wycoff-Jagodzinski notation (ch) is shown in blue on the right side demonstrating hc $\mathrm{h}_{3}$ ordering.

The XRD patterns of the acid-cleaned and water-washed powders are shown in Figure 4a. Peaks belonging to three phases are identified. One set of reflections belong to the major phase and can be attributed to a hexagonal $\mathrm{P}_{3} / \mathrm{mmc}$ symmetry with lattice parameters a and c of $\sim 3.01$ and $\sim 19.56 \AA$, respectively. Another set belong to a minor phase with Fm $\overline{3 m}$ cubic symmetry with a lattice parameter a $4.298 \AA$ (Figure 4a). A 1-3 wt \% impurity $\mathrm{Al}_{2} \mathrm{O}_{3}$ phase is also present. Although the symmetry and lattice parameters are reminiscent to what is expected from a MAX phase with $n=2,{ }^{37}$ an attempt to refine such a model, that is $(\mathrm{W}, \mathrm{Ti})_{3} \mathrm{AlC}_{2}$ with either ordered $\mathrm{W} / \mathrm{Ti}$ layers or disordered ones, ${ }^{38}$ resulted in extremely poor agreement between model and experiment for all cases (not shown). However, assuming the hexagonal space group $\mathrm{P}_{3} / \mathrm{mmc}$ for an $\mathrm{Al}$-free phase of $(\mathrm{W}, \mathrm{Ti})_{4} \mathrm{C}_{4-\mathrm{x}}(\mathrm{x} \approx 1.4)$ with cell parameters, $\mathrm{a} \approx 3.08 \AA$ and $\mathrm{c}$ $\approx 20.47 \AA$, obtained from the HRSTEM images (Figure 3) are in good agreement with those obtained from the XRD patterns, viz. a $3.01 \AA$, and c $\sim 19.56 \AA$.

It is worth repeating here that to further test the role of $\mathrm{Al}$, we sintered a similar stoichiometric ratio of W/Ti/C powders with no $\mathrm{Al}$ under the same conditions. The resulting material crystallized in a mixture of $\mathrm{TiC}_{\mathrm{x}}$ and $\mathrm{W}_{2} \mathrm{C}$ (Supporting Information, Figure S1), and (W,Ti) ${ }_{4} \mathrm{C}_{4-\mathrm{x}}$ was not formed. Since the synthesis conditions $\left(160{ }^{\circ} \mathrm{C}, 4 \mathrm{~h}\right)$ chosen here are typical of several Al-containing MAX phases, such as $\mathrm{Ta}_{4} \mathrm{AlC}_{3}$, $\mathrm{Mo}_{2} \mathrm{TiAlC}_{2}$, and $\mathrm{Mo}_{2} \mathrm{Ti}_{2} \mathrm{AlC}_{3},{ }^{11-13}$ it is quite unlikely that the $\mathrm{Al}$ simply evaporated away in the tube furnace. 

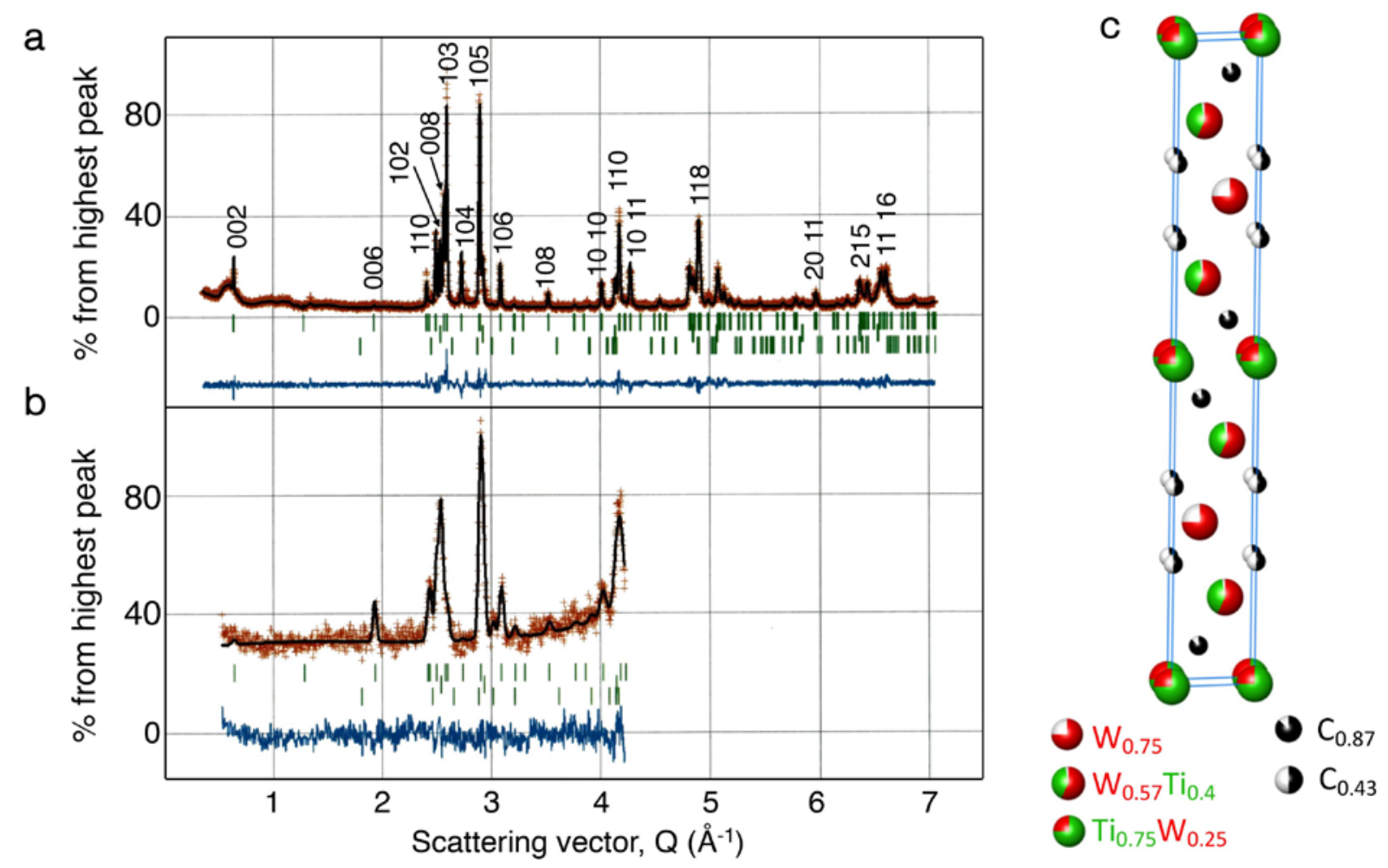

Figure 4| Crystal structure of (W, Ti) ${ }_{4} \mathrm{C}_{4-\mathrm{x}}$. (a,b) Joint Rietveld analysis of (a) XRD, and (b) NPD data (red crosses). The refined model (solid black line) is comprised of three phases: hexagonal P63/mmc that describes the major phase with the refined formula of $\mathrm{W}_{2.1(1)} \mathrm{Ti}_{1.6(1)} \mathrm{C}_{2.6(1)}$ (first row of tags), cubic Fm $\overline{3 \mathrm{~m}}$ that describes the minor (W,Ti)C phase (second row of tags), and a minor Al2O3 impurity phase (third row of tags). The quality of the fit is represented by the difference between model and observed data (blue lines at the bottom). (c) Suggested structure for $\mathrm{W}_{2.1(1)} \operatorname{Ti}_{1.6(1)} \mathrm{C}_{2.6(1)}$, with random $\mathrm{C}$ and $\mathrm{W}$ vacancies and $\mathrm{W}$, Ti intermixing in different planes.

Since a large number of occupancy parameters had to be determined, a simultaneous Rietveld analysis of both the XRD and NPD results was carried out. Using this method enables individual refinements of each element occupancy for each crystallographic site. The model included the major hexagonal $(\mathrm{W}, \mathrm{Ti})_{4} \mathrm{C}_{4-\mathrm{x}}$, cubic carbide (W,Ti)C, and $\mathrm{Al}_{2} \mathrm{O}_{3}$ phases. On the basis of the STEM result, the starting $(\mathrm{W}, \mathrm{Ti})_{4} \mathrm{C}_{4-\mathrm{x}}$ structure was assumed to have the hexagonal $\mathrm{P}_{3} / \mathrm{mmc}$ space group with the following atomic positions: $(\mathrm{W}, \mathrm{Ti})_{1}$ in $2 \mathrm{~d}(1 / 3,2 / 3,3 / 4),(\mathrm{W}, \mathrm{Ti})_{2}$ in $4 \mathrm{f}(1 / 3,2 / 3, \mathrm{z} \sim 1 / 8),(\mathrm{W}, \mathrm{Ti})_{3}$ in $2 \mathrm{a}(0,0,0)$. For the carbon positions we assumed $C_{1}$ in $4 \mathrm{e}(0,0, \mathrm{z} \sim 1 / 3)$, and $\mathrm{C}_{2}$ in $4 \mathrm{f}(1 / 3,2 / 3, \mathrm{z} \sim 0)$, covering all the octahedral sites between the M layers. The starting occupancies used were a ratio of 2:1 for W/Ti, and half occupancy for $\mathrm{C}_{1}$ and full occupancy for $\mathrm{C}_{2}$. For the (W,Ti)C minor impurity phase, we used the same cubic Fm $\overline{3 m}$ space group of $\mathrm{TiC}^{39}$ with a cell parameter of $\sim 4.29 \AA$. According to ref 25 , this cell parameter corresponds to $\left(\mathrm{W}_{0.4} \mathrm{Ti}_{0.6}\right) \mathrm{C}$, which served as a starting value for the relative Ti/W occupancy of this minority phase. Elemental occupancies were refined with no constraints for the major hexagonal phase and minor cubic phase. In addition, all models allowed for the refinement of the phases' cell parameters, isotropic thermal displacements for all crystallographic sites in $(\mathrm{W}, \mathrm{Ti})_{4} \mathrm{C}_{4-x}$ and their counterparts in the cubic phase, atomic 
positions, phase fractions, linear interpolation type background, ${ }^{33}$ Lorentzian-type peak broadening for all phases, and instrument asymmetry parameters. Excellent fit between the same structural model and the observed XRD (Figure 4a), and NPD (Figure 4b) data was achieved. Table 1 summarizes the refined values obtained from the Rietveld refinements.

According to our refinement, the structure consists of one Ti-rich layer, presented as the (W,Ti) $)_{3}$ sites in Table 1, two $\mathrm{W}$ rich layers on the $(\mathrm{W}, \mathrm{Ti})_{2}$ sites and one pure $\mathrm{W}$ layer with $\sim 25 \%$ vacancies, presented as the $(\mathrm{W}, \mathrm{Ti})_{1}$ sites in Table 1 . The occupancy of $\mathrm{C}$ and atomic positions were also accurately determined with an overall $\sim 35 \%$ of disordered $\mathrm{C}$ vacancies per formula unit for $(\mathrm{W}, \mathrm{Ti})_{4} \mathrm{C}_{4-\mathrm{x}}$. The unit cell is shown in Figure 4c, which as noted above has a hc 3 stacking ordering. The twin mirror h plane is pure $\mathrm{W}$ with $\sim 25 \%$ vacancies and the two immediate adjacent layers are almost equimolar in $\mathrm{W}$ and $\mathrm{Ti}$, viz. $\mathrm{W} 0.574(2) \mathrm{Ti}_{0.40(4)}$. The second adjacent layer to the mirror plane is Ti-rich, with almost a 1:3 W/Ti ratio, viz. $\mathrm{W}_{0.25(1)} \operatorname{Ti}_{0.78(4)}$.

The $\mathrm{C}$ atoms occupy the interstitial sites and their total per formula unit is estimated to be 2.6. On the basis of our NPD results, there is no evidence for ordering of the $C$ vacancies and all the interstitial layers are partly occupied by $\mathrm{C}$ atoms. It is important to note that since all the interstitial sites are partially filled with $\mathrm{C}$, the $(\mathrm{W}, \mathrm{Ti}){ }_{4} \mathrm{C}_{4-\mathrm{x}}$ formula with $\sim 35 \% \mathrm{C}$ vacancies $(\mathrm{x}=1.4)$ is the correct notation. However, if future work shows evidence for C-ordering, then the correct notation is $(\mathrm{W}, \mathrm{Ti})_{4} \mathrm{C}_{3}$, in which it is implicitly assumed that at some point the $\mathrm{C}$ vacancies would order. ${ }^{35,36,40}$ If such ordering is not forthcoming, then the correct notation is $(\mathrm{W}, \mathrm{Ti}){ }_{4} \mathrm{C}_{4}$ phase as assumed in this study. Further assessment is needed to identify the best notation. For the minority (W,Ti)C cubic phase, the refined W/Ti ratio was 0.44(5)/0.65(7) in agreement with the previous results, ${ }^{25}$ adding to the reliability of the refinement process.

Combining EDX and the XRD and NPD refinement results, we conclude that chemistry of this carbide is most probably $\mathrm{W}_{2.1(1)} \mathrm{Ti}_{1.6(1)} \mathrm{C}_{2.6(1)}$. Note that the uncertainties in the occupancies determined by the refinement process are statistical in nature. The final formula is reported with larger uncertainties covering the systematic uncertainty as well. In our previous work, we argued that in the out-of-plane ordered MAX phases, the M elements, whose binary carbides did not crystallize in the rock salt structure avoided the center of the MX blocks. ${ }^{13,41}$ The same principle appears to apply here. The pure W layers are sitting in an ABA, or hexagonal, arrangement. It is only when these layers are alloyed with $\mathrm{Ti}$, that they are no longer sitting in a hexagonal arrangement, but rather in a face-centered cubic (fcc), ABC, type arrangement. This is consistent with the fact that it is only when the Ti/W ratio $>1$ that the rock salt carbide structures become stable. ${ }^{25}$ Note that in the layers adjacent to the mirror planes the W/Ti ratio is only slightly over 1:1. 
Table 1| Structural parameters determined from simultaneous Rietveld analysis of (W,Ti) ${ }_{4} \mathrm{C}_{3} \mathrm{NPD}$ and XRD data. The refined formula is $\mathrm{W}_{2.1(1)} \mathrm{Ti}_{1.6(1)} \mathrm{C}_{2.6(1)}$ This phase orders in the hexagonal $\mathrm{P}_{3} / \mathrm{mmc}$ space-group with (W,Ti) 1 positioned in $2 \mathrm{~d}(1 / 3,2 / 3,3 / 4),(\mathrm{W}, \mathrm{Ti})_{2}$ in $4 \mathrm{f}(1 / 3,2 / 3, \mathrm{z} 1 / 8)$, (W,Ti) 3 in $2 \mathrm{a}(0,0,0), \mathrm{C}_{1}$ in $4 \mathrm{e}(0,0, \mathrm{z} 1 / 3)$, and $\mathrm{C}_{2}$ in $4 \mathrm{f}(1 / 3,2 / 3, \mathrm{z} 0)$. The minor $(\mathrm{W}, \mathrm{Ti}) \mathrm{C}$ phase orders in the cubic Fm $\overline{3} \mathrm{~m}$ space-group with (W,Ti) positioned in $4 \mathrm{a}(0,0,0)$, and $\mathrm{C}$ in $4 \mathrm{~b}(1 / 2,1 / 2,1 / 2)$; a, and c are cell parameters; wt.\% is a phase's weight percent, $\mathrm{B}_{\text {iso }}\left(\mathrm{B}_{\mathrm{ov}}\right)$ is individual (overall) atomic thermal displacement parameter; occ. is occupancy; $\mathrm{R}_{\mathrm{F}}$ is individual phase agreement factor; $\mathrm{R}_{\exp }$ is overall expected agreement factor, and $\mathrm{R}_{\mathrm{wp}}$ is the weighted profile agreement factor. Note that $\chi^{2}=\left(\mathrm{R}_{\mathrm{wp}} / \mathrm{R}_{\exp }\right)^{2,33}$ Numbers in parentheses represent one standard deviation of the last significant digits determined by the refinement process. A small $\mathrm{Al}_{2} \mathrm{O}_{3}$ impurity also exists

\begin{tabular}{|c|c|c|c|}
\hline Phase & Parameters & & $\begin{array}{c}\text { Refined } \\
\text { values }\end{array}$ \\
\hline \multirow{23}{*}{$(\mathrm{W}, \mathrm{Ti})_{4} \mathrm{C}_{3}$} & a $(\AA)$ & & $3.00880(7)$ \\
\hline & c $(\AA)$ & & 19.5633(6) \\
\hline & wt.\% & NPD & $77(5)$ \\
\hline & Wt.\% & XRD & $79(6)$ \\
\hline & \multirow{3}{*}{$(\mathrm{W}, \mathrm{Ti})_{1}$} & $\mathrm{~B}_{\text {iso }}\left(\AA^{2}\right)$ & $0.25(8)$ \\
\hline & & W осc. & $0.75(1)$ \\
\hline & & Ti осс. & $0^{\perp}$ \\
\hline & \multirow{4}{*}{$(\mathrm{W}, \mathrm{Ti})_{2}$} & $\mathrm{z}$ & $0.1275(2)$ \\
\hline & & $\mathrm{B}_{\text {iso }}\left(\AA^{2}\right)$ & $0.885(8)$ \\
\hline & & W осc. & $0.574(2)$ \\
\hline & & Ti осс. & $0.40(4)$ \\
\hline & \multirow{3}{*}{$(\mathrm{W}, \mathrm{Ti})_{3}$} & $B_{\text {iso }}\left(\AA^{2}\right)$ & $1.3(2)$ \\
\hline & & W occ. & $0.25(1)$ \\
\hline & & Ti осc. & $0.78(4)^{\dagger}$ \\
\hline & \multirow{2}{*}{$\mathrm{C}_{1}{ }^{\&}$} & $\mathrm{Z}$ & $0.3098(3)$ \\
\hline & & occ. & $0.425(4)$ \\
\hline & \multirow{2}{*}{$\mathrm{C}_{2}{ }^{\&}$} & $\mathrm{z}$ & $-0.0640(2)$ \\
\hline & & occ. & $0.87(1)$ \\
\hline & $\alpha$ & & $0.14(2)$ \\
\hline & $\beta$ & & $0.58(9)$ \\
\hline & $\delta$ & & $0.41(3)$ \\
\hline & \multirow{2}{*}{$\mathrm{R}_{\mathrm{F}}$} & NPD & 6.75 \\
\hline & & XRD & 14.2 \\
\hline \multirow{8}{*}{$(\mathrm{W}, \mathrm{Ti}) \mathrm{C}$} & a $(\AA)$ & & $4.2942(7)$ \\
\hline & \multirow[t]{2}{*}{$w t \%$} & NPD & $19(4)$ \\
\hline & & XRD & 20(1) \\
\hline & $\mathrm{W}$ & occ. & $0.44(5)$ \\
\hline & $\mathrm{Ti}$ & occ. & $0.65(7)$ \\
\hline & $B_{o v}$ & & $0.84(1)$ \\
\hline & \multirow{2}{*}{$\mathrm{R}_{\mathrm{F}}$} & NPD & 2.83 \\
\hline & & XRD & 0.307 \\
\hline \multirow[t]{2}{*}{$\overline{R_{\text {exp }}}$} & & NPD & 7.58 \\
\hline & & XRD & 7.17 \\
\hline \multirow[t]{2}{*}{$\mathrm{R}_{\mathrm{wp}}$} & & NPD & 10.4 \\
\hline & & XRD & 7.12 \\
\hline
\end{tabular}

${ }^{\perp}$ Fixed to zero after it was refined to a small negative value. 
${ }^{\&} B_{\text {iso }}$ fixed to 0.75 .

$\dagger$ The sum of $\mathrm{W}+\mathrm{Ti}$ occupancies in $(\mathrm{W}, \mathrm{Ti})_{3}$ is 1.03 . In our refinements, we did not set the site occupancies to full occupancy or other value. Individual $\mathrm{W}, \mathrm{Ti}$, and $\mathrm{C}$ occupancies are refined with no constraint.

\section{CONCLUSIONS}

In summary, a ternary carbide with a nominal composition of $(\mathrm{W}, \mathrm{Ti})_{4} \mathrm{C}_{4-\mathrm{x}}$, with $\mathrm{x} \approx 1.4$, actual composition $\approx \mathrm{W}_{2.1(1)} \mathrm{Ti}_{1.6(1)} \mathrm{C}_{2.6(1)}$, was synthesized. This phase was made by heating $\mathrm{W}, \mathrm{Ti}$, Al, and $\mathrm{C}$ powders in a 2:1:1.1:2 molar ratio at $1600{ }^{\circ} \mathrm{C}$ for $4 \mathrm{~h}$. In the absence of $\mathrm{Al}$, the phase does not form suggesting that $\mathrm{Al}$ somehow aids in nucleating this carbide. This phase has an ordered layered hexagonal structure with $\mathrm{P} 6_{3} / \mathrm{mmc}$ space group and cell parameters a = 3.0088(7) $\AA$ and c $=19.5633(6)$ $\AA$ with two formula units per unit cell. The stacking sequence of the M layers is ABCBACBCA, wherein every fourth layer, comprised of $\mathrm{W}$ only and underlined, is a twin mirror plane with 25\% vacancies. The adjacent atomic layers to the twin mirror planes are $\mathrm{W}$-rich $(\mathrm{W}, \mathrm{Ti})$ layers and the second adjacent layers are Ti-rich (Ti,W) layers. The $\mathrm{C}$ atoms fill in the interstitial sites. However, instead of $4 \mathrm{C}$ atoms per formula unit, we only measure 2.6, implying the presence of $\mathrm{C}$-vacancies. It is important to note that we did not find any evidence for the ordering of the $\mathrm{C}$ vacancies in the NPD data.

A more succinct description of the structure is hc3, which is, to our knowledge, the first of its kind to be experimentally realized. Since there is no reason to believe this phase is a one of, it is more likely than not to be the first in a potentially large family of ordered layered ternary transition metal carbides and possibly nitrides. The combination of heavy and light transition metals in this structure can also help modifying their electronic and electrochemical properties making these materials potentially favorable for different targeted applications.

\section{Acknowledgments}

M.B. and J.R. acknowledge support from the Swedish Foundation for Strategic Research (SSF) through a Synergy Grant. J.R. and L.H. also acknowledge support from the Knut and Alice Wallenberg (KAW) Foundation, for a Fellowship Grant, Project funding (KAW 2015.0043), and for support to the Linköping Electron Microscopy Laboratory. The Swedish Research Council is gratefully acknowledged through Projects 642-2013-8020 and 621-2014-4890. The calculations (not shown in this study) were carried out using supercomputer resources provided by the Swedish National Infrastructure for Computing (SNIC) at the National Supercomputer Centre (NSC), the High Performance Computing Center North (HPC2N), and the PDC Center for High Performance Computing. 


\section{References}

1. Oyama, S. T.; Schlatter, J. C.; Metcalfe III, J. E.; Lambert Jr, J. M., Preparation and characterization of early transition metal carbides and nitrides. Industrial \& Engineering Chemistry Research 1988, 27 (9), 1639-1648.

2. Levy, R.; Boudart, M., Platinum-like behavior of tungsten carbide in surface catalysis. Science 1973, 181 (4099), 547-549.

3. Zhong, Y.; Xia, X.; Shi, F.; Zhan, J.; Tu, J.; Fan, H. J., Transition Metal Carbides and Nitrides in Energy Storage and Conversion. Advanced Science 2016, 3 (5), 1500286.

4. Bloom, D. S.; Grant, N. The system chromium-carbon. JOM 1950, 2 (1), 41-46.

5. Kudielka, H.; Rohde, H., Strukturuntersuchungen an Carbosulfiden von Titan und Zirkon. Z. Kristalogr. 1960, 114, 447.

6. Jeitschko, W.; Nowotny, H.; Benesovsky, F., Kohlenstoffhaltige ternäre Verbindungen (H-Phase). Monatshefte für Chemie / Chemical Monthly 1963, 94 (4), 672-676.

7. Barsoum, M. W., The Mn+1AXn phases: A new class of solids : Thermodynamically stable nanolaminates. Progress in Solid State Chemistry 2000, 28 (1-4), 201-281.

8. Zhou, J.; Zha, X.; Zhou, X.; Chen, F.; Gao, G.; Wang, S.; Shen, C.; Chen, T.; Zhi, C.; Eklund, P.; Du, S.; Xue, J.; Shi, W.; Chai, Z.; Huang, Q., Synthesis and Electrochemical Properties of Two-Dimensional Hafnium Carbide. ACS Nano 2017, 11, 3841-3850.

9. Zhou, J.; Zha, X.; Chen, F. Y.; Ye, Q.; Eklund, P.; Du, S.; Huang, Q., A Two-Dimensional Zirconium Carbide by Selective Etching of Al3C3 from Nanolaminated Zr3Al3C5. Angewandte Chemie 2016, 128 (16), 5092-5097.

10. Naguib, M.; Kurtoglu, M.; Presser, V.; Lu, J.; Niu, J.; Heon, M.; Hultman, L.; Gogotsi, Y.; Barsoum, M. W., Two-Dimensional Nanocrystals Produced by Exfoliation of Ti3AlC2. Advanced Materials 2011, 23 (37), 4248-4253.

11. Naguib, M.; Mashtalir, O.; Carle, J.; Presser, V.; Lu, J.; Hultman, L.; Gogotsi, Y.; Barsoum, M. W., TwoDimensional Transition Metal Carbides. ACS Nano 2012, 6 (2), 1322-1331.

12. Anasori, B.; Halim, J.; Lu, J.; Voigt, C. A.; Hultman, L.; Barsoum, M. W., Mo2TiAlC2: A new ordered layered ternary carbide. Scripta Materialia 2015, 101, 5-7.

13. Anasori, B.; Dahlqvist, M.; Halim, J.; Moon, E. J.; Lu, J.; Hosler, B. C.; Caspi, E. a. N.; May, S. J.; Hultman, L.; Eklund, P.; Rosén, J.; Barsoum, M. W., Experimental and theoretical characterization of ordered MAX phases Mo2TiAlC2 and Mo2Ti2AlC3. Journal of Applied Physics 2015, 118 (9), 094304.

14. Meshkian, R.; Tao, Q.; Dahlqvist, M.; Lu, J.; Hultman, L.; Rosen, J., Theoretical stability and materials synthesis of a chemically ordered MAX phase, Mo2ScAlC2, and its two-dimensional derivate Mo2ScC2 MXene. Acta Materialia 2017, 125, 476-480.

15. Caspi, E. N.; Chartier, P.; Porcher, F.; Damay, F.; Cabioc'h, T., Ordering of (Cr,V) Layers in Nanolamellar (Cr0.5V0.5)n+1AlCn Compounds. Materials Reseach Letters 2014, 1-7.

16. Liu, Z.; Zheng, L.; Sun, L.; Qian, Y.; Wang, J.; Li, M., (Cr2/3Ti1/3)3AlC2 and (Cr5/8Ti3/8)4AlC3: New MAX-phase Compounds in Ti-Cr-Al-C System. Journal of the American Ceramic Society 2014, 97 (1), 67-69.

17. Dahlqvist, M.; Lu, J.; Meshkian, R.; Tao, Q.; Hultman, L.; Rosen, J., Prediction and synthesis of a family of atomic laminate phases with Kagomé-like and in-plane chemical ordering. Science Advances 2017, 3 (7).

18. Tao, Q.; Dahlqvist, M.; Lu, J.; Kota, S.; Meshkian, R.; Halim, J.; Palisaitis, J.; Hultman, L.; Barsoum, M. W.; Persson, P. O. Å.; Rosen, J., Two-dimensional Mo1.33C MXene with divacancy ordering prepared from parent 3D laminate with in-plane chemical ordering. Nature Communications 2017, 8, 14949.

19. Meshkian, R.; Dahlqvist, M.; Lu, J.; Wickman, B.; Halim, J.; Thornberg, J.; Tao, Q.; Li, S.; Intikhab, S.; Snyder, J.; Barsoum, M. W.; Yildizhan, M.; Palisaitis, J.; Hultman, L.; Persson, P. O. A.; Rosen, J., WBased Atomic Laminates and Their 2D Derivative W1.33C MXene with Vacancy Ordering. Adv Mater 2018, 30 (21), e1706409.

20. Hu, C.; Lai, C. C.; Tao, Q.; Lu, J.; Halim, J.; Sun, L.; Zhang, J.; Yang, J.; Anasori, B.; Wang, J.; Sakka, Y.; Hultman, L.; Eklund, P.; Rosen, J.; Barsoum, M. W., Mo2Ga2C: a new ternary nanolaminated carbide. Chemical Communications 2015, 51 (30), 6560-6563.

21. Lai, C. C.; Meshkian, R.; Dahlqvist, M.; Lu, J.; Näslund, L. Å.; Rivin, O.; Caspi, E. N.; Ozeri, O.; Hultman, L.; Eklund, P.; Barsoum, M. W.; Rosen, J., Structural and chemical determination of the new nanolaminated carbide Mo2Ga2C from first principles and materials analysis. Acta Materialia 2015, 99, 157-164. 
22. Fashandi, H.; Dahlqvist, M.; Lu, J.; Palisaitis, J.; Simak, S. I.; Abrikosov, I. A.; Rosen, J.; Hultman, L.; Andersson, M.; Spetz, A. L., Synthesis of Ti3AuC2, Ti3Au2C2 and Ti3IrC2 by noble metal substitution reaction in Ti3SiC2 for high-temperature-stable Ohmic contacts to SiC. Nature materials 2017, 16 (8), 814.

23. Mckenna, P. M., Tungsten titanium carbide, wtic. Google Patents: 1938.

24. Nowotny, H.; Parthe, E.; Kieffer, R.; Benesovsky, F., Das Dreistoffsystem Titan-Wolfram-Kohlenstoff. Zeitschrift fur Metallkunde 1954, 45 (3), 97-101.

25. Denbnovetskaya, E. N., Preparation of solid solutions of some complex carbides of the transition metals. Soviet Powder Metallurgy and Metal Ceramics 1967, 6 (3), 194-197.

26. Lonnberg, B.; Lundstrom, T., Crystal-growth of Solid-solutions of the Group-IV-VI Transition-Metal Monocarbides from Molten Aluminum. Chemica Scripta 1988, 28 (1), 25-32.

27. Rudy, E., Constitution of ternary titanium-tungsten-carbon alloys. Journal of the Less Common Metals 1973, 33 (2), 245-273.

28. Jeitschko, W.; Behrens, R., Ternary carbides with Ho2Cr2C3 and UMoC2 type structure. Zeitschrift fuer Metallkunde 1986, 77 (12), 788-793.

29. Hugosson, H. W.; Engqvist, H., The connection between the electronic structure and the properties of binderless tungsten carbides. International Journal of Refractory Metals and Hard Materials 2003, 21 (1-2), 55-61.

30. Kurlov, A. S.; Gusev, A. I., Tungsten carbides and W-C phase diagram. Inorganic Materials 2006,42 (2), 121-127.

31. Chang, R.; Graham, L. J., Low-Temperature Elastic Properties of ZrC and TiC. Journal of Applied Physics 1966, 37 (10), 3778-3783.

32. Rietveld, H., A profile refinement method for nuclear and magnetic structures. Journal of Applied Crystallography 1969, 2 (2), 65-71.

33. Rodríguez-Carvajal, J., Recent advances in magnetic structure determination by neutron powder diffraction. Physica B: Condensed Matter 1993, 192 (1-2), 55-69.

34. Barsoum, M. W.; Basu, S., Kinking Nonlinear Elastic Solids. In Encyclopedia of Materials Science and Technology, Buschow, K. H. J.; Cahn, R. W.; Flemings, M. C.; Ilschner, B.; Kramer, E. J.; Mahajan, S.; Veyssiere, P., Eds. Elsevier: Oxford, 2010.

35. Parthe, E.; Yvon, K., On the crystal chemistry of the close packed transition metal carbides. II. A proposal for the notation of the different crystal structures. Acta Crystallographica Section B 1970, 26 (2), $153-163$.

36. Demyashev, G. M., Review: Transition metal-based nanolamellar phases. Progress in Materials Science 2010, 55 (7), 629-674.

37. Barsoum, M. W., MAX phases: properties of machinable ternary carbides and nitrides. John Wiley \& Sons: 2013.

38. Dahlqvist, M.; Rosen, J., Order and disorder in quaternary atomic laminates from first-principles calculations. Phys Chem Chem Phys 2015, 17 (47), 31810-21.

39. Elliott, R. O.; Kempter, C. P., Thermal Expansion of Some Transition Metal Carbides. The Journal of Physical Chemistry 1958, 62 (5), 630-631.

40. Gusev, A.; Kurlov, A.; Lipatnikov, V. Atomic and vacancy ordering in carbide $\zeta-T a 4 C 3-x(0.28 \leqslant x \leqslant 0.40)$ and phase equilibria in the Ta-C system. J. Solid State Chem. 2007, 180 (11), 3234-3246.

41. Anasori, B.; Xie, Y.; Beidaghi, M.; Lu, J.; Hosler, B. C.; Hultman, L.; Kent, P. R. C.; Gogotsi, Y.; Barsoum, M. W. Two-Dimensional, Ordered, Double Transition Metals Carbides (MXenes). ACS Nano 2015, 9 (10), 9507-9516. 
TOC

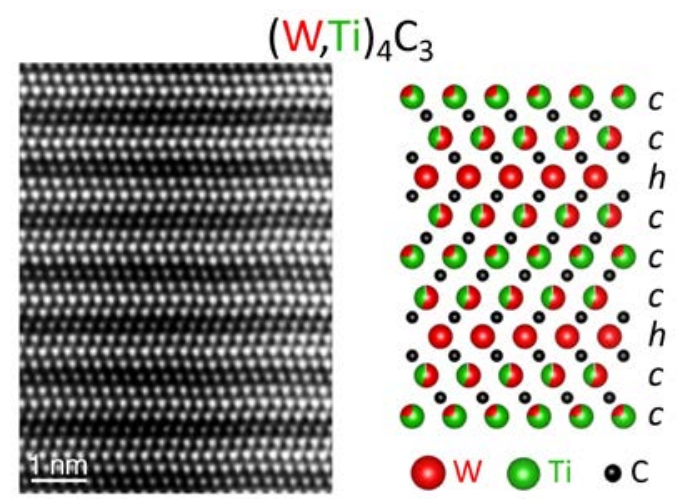




\title{
A Tungsten-Based Nanolaminated Ternary Carbide: $(\mathrm{W}, \mathbf{T i})_{4} \mathrm{C}_{4-x}$
}

\author{
Babak Anasori,,${ }^{1,2,}{ }^{*}$ Jun Lu, ${ }^{3, *}$ Oleg Rivin, ${ }^{4}$ Martin Dahlqvist, ${ }^{3}$ Joseph Halim, ${ }^{3}$ Cooper \\ Voigt, ${ }^{1}$ Johanna Rosen, ${ }^{3}$ L. Hultman, ${ }^{3}$ Michel W. Barsoum, ${ }^{1, *}$ El'ad N. Caspi,,${ }^{1,4}$ \\ ${ }^{1}$ Department of Materials Science \& Engineering, Drexel University, Philadelphia, PA 19104, USA \\ ${ }^{2}$ A. J. Drexel Nanomaterials Institute, Drexel University, Philadelphia, PA 19104, USA \\ ${ }^{3}$ Thin Film Physics Division, Department of Physics, Chemistry and Biology (IFM), Linköping University, \\ SE-581 83 Linköping, Sweden \\ ${ }^{4}$ Physics Department, Nuclear Research Centre - Negev, 84190 Beer-Sheva, Israel \\ ${ }^{*}$ Corresponding authors: \\ anasori@drexel.edu (B. Anasori) \\ Jun.lu@liu.se (J. Lu) \\ barsoumw@drexel.edu (M.W. Barsoum)
}

\section{An overview on binary and ternary tungsten carbides}

The discovery of MXenes encouraged the TMC community to look for other layered ternary carbides that can be used as MXene precursors. Many new phenomena and new structures were found during this exploration. For instance, in the Mo, Ga and $\mathrm{C}$ system, besides the "usual" MAX $\mathrm{Mo}_{2} \mathrm{GaC}$ phase, a new layered structure was found, $\mathrm{Mo}_{2} \mathrm{Ga}_{2} \mathrm{C} \cdot{ }^{1-2} \mathrm{Mo}_{2} \mathrm{Ga}_{2} \mathrm{C}$ has similar elements as the MAX phases, however its structure differs from the regular MAX phase by having two, instead of one, A-layers $(\mathrm{Ga})$ between the $\mathrm{M}_{2} \mathrm{X}\left(\mathrm{Mo}_{2} \mathrm{C}\right)$ layers.

Another discovery has been the synthesis of Mo-Al containing MAX phases. For the Mocontaining $\mathrm{M}_{n+1} \mathrm{AC}_{n} \mathrm{MAX}$ phases, only $n=1$ was reported before 2015 and $n=2,3$ have never been successfully synthesized, possibly because the Mo atoms tend to avoid $f c c$ arrangement with $\mathrm{C}$-atoms. In 2015, it was discovered that by introducing $\mathrm{Ti}$ in the middle $\mathrm{M}$ layer of a $\mathrm{M}_{3} \mathrm{AX}_{2}$ MAX phase and having Mo atoms on the outer M layers, the structure becomes stable resulting in the new ordered quaternary phase, $\mathrm{Mo}_{2} \mathrm{TiAlC}_{2} \cdot{ }^{3-4} \mathrm{~A}$ similar material, $\mathrm{Mo}_{2} \mathrm{ScAlC}_{2}$, was realized thereafter. ${ }^{5}$ Using a similar approach, it was possible to make a $\mathrm{M}_{4} \mathrm{AlC}_{3}$ structure, with $\mathrm{M}$ layers ordering of Mo-Ti-Ti-Mo and $\mathrm{C}$ filling the octahedral interstitial sites. ${ }^{4}$ Thus, it is possible to make new layered structures containing heavy VIB transition metal using early transition metal's assistance.

In 2017, a new level of ordering in the MAX phases was discovered, in which two different M elements were in-plane ordered. ${ }^{6-7}$ This new family of MAX derivatives, denoted as $i$-MAX enabled the incorporation of new elements into the MAX phase family (e.g., Y and W), as well as opened the path to novel 2D MXenes. ${ }^{5,7-8}$ This recent finding clearly demonstrates the vast potential the materials science community still has in discovering novel MAX phases, TMCs, and related materials.

To date, only two $\mathrm{W}$-containing MAX phases has been discovered: the i-MAX $\left(\mathrm{W}_{2 / 3} \mathrm{Sc}_{1 / 3}\right)_{2} \mathrm{AlC}$ and $\left(\mathrm{W}_{2 / 3} \mathrm{Y}_{1 / 3}\right)_{2} \mathrm{AlC}$ phases. ${ }^{8}$ Several theoretical studies have predicted the stability (or metastability) of W-containing MAX phases and explored their expected properties, with $\mathrm{W}_{2} \mathrm{AlC}$ being the most studied among them. ${ }^{9-13}$ Of special note is the very large bulk modulus expected for $\mathrm{W}_{2} \mathrm{AC}$. At $\sim 270 \mathrm{GPa}$ (for $\mathrm{A}=\mathrm{Al}, \mathrm{Ga}$ ), it is one of the largest calculated for $n=1 \mathrm{MAX}$ phases, which is not too surprising, considering the bulk modulus of the binary tungsten carbide is reported to be $\sim 700 \mathrm{GPa} .{ }^{9}{ }^{14}$ The combination of $\mathrm{W}$ with other transition metals on the $\mathrm{M}$ sites of the MAX phases was also considered, and predicted to be stable ${ }^{15-16}$, with the combination of (W,Ti) resulting in a chemically ordered layered structure for the most stable case. ${ }^{16}$ 


\section{Supporting Information}

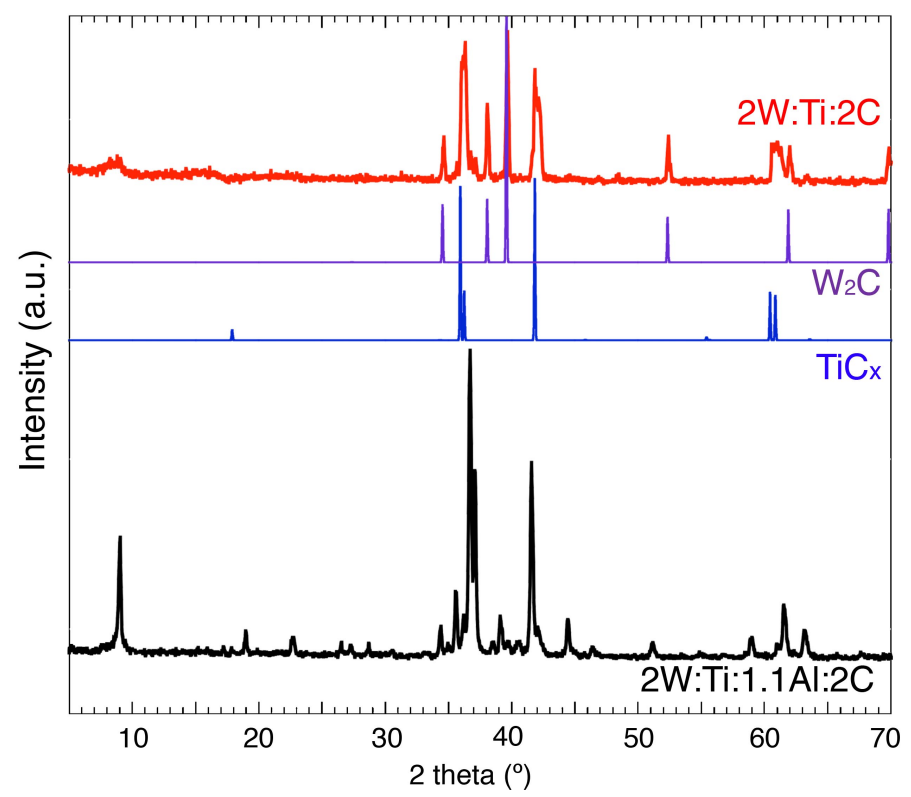

Figure S1| Effect of $\mathrm{Al}$ as a catalysis for $(\mathbf{W}, \mathbf{T i})_{4} \mathbf{C}_{4-x}$ formation. XRD pattern of a sample made with no $\mathrm{Al}$ from a mixture of W:Ti:C 2:1:2 (red top pattern) is compared with a sample made with addition of $\mathrm{Al}$ in the raw mix from W:Ti:Al:C 2:1:1.1:2 (black bottom pattern). Both samples made at the same condition of $1600{ }^{\circ} \mathrm{C}$ under $\mathrm{Ar}$ flow for $4 \mathrm{~h}$. When no $\mathrm{Al}$ is used in the synthesis, the resulting sample is a mixture of non-stoichiometric $\mathrm{TiC}_{\mathrm{x}}{ }^{17}$ and hexagonal $\mathrm{W}_{2} \mathrm{C} .{ }^{18}$ When $\mathrm{Al}$ is used in the synthesis (2W:Ti:1.1Al:2C) the resulting sample has the $(\mathrm{W}, \mathrm{Ti})_{4} \mathrm{C}_{4-x} \mathrm{XRD}$ pattern, with some impurities such as $\mathrm{Al}_{4} \mathrm{~W}$.

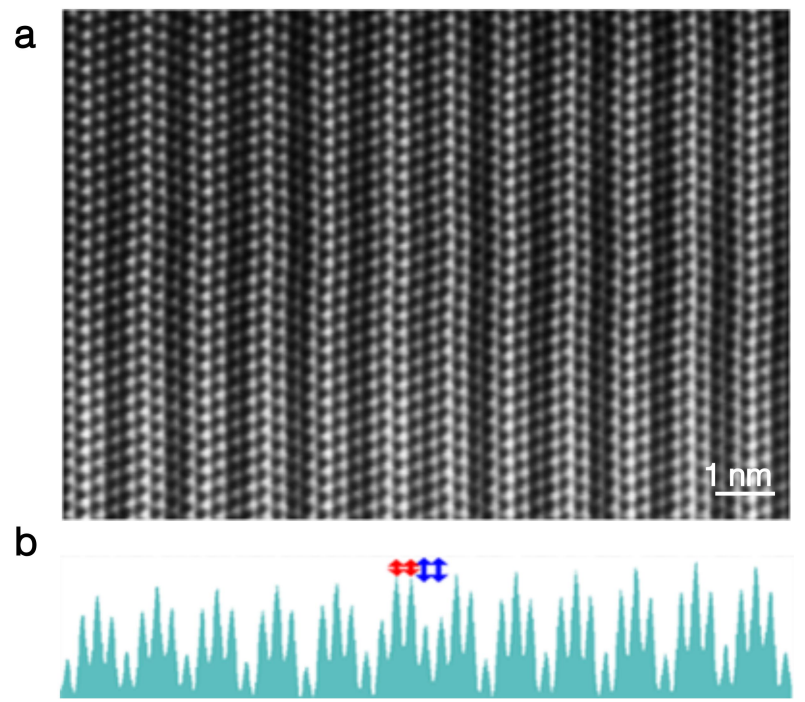

Figure S2| Stacking fault in $(\mathbf{W}, \mathbf{T i})_{4} \mathbf{C}_{4-x}$ structure. (a) HRSTEM along the [11 $\left.\overline{\mathbf{2}} 0\right]$ with (b) intensity profile along [0001] direction. Two bright layers with high intensities (W-rich, marked with two red arrows) are adjacent to two drak grey with lower intensities, (lower W content, marked by two blue arrows), showing a stacking fault in the structure. 


\section{Supporting Information}

\section{References}

1. Hu, C.; Lai, C. C.; Tao, Q.; Lu, J.; Halim, J.; Sun, L.; Zhang, J.; Yang, J.; Anasori, B.; Wang, J.; Sakka, Y.; Hultman, L.; Eklund, P.; Rosen, J.; Barsoum, M. W., $\mathrm{Mo}_{2} \mathrm{Ga}_{2} \mathrm{C}$ : a new ternary nanolaminated carbide. Chemical Communications 2015, 51 (30), 6560-6563.

2. Lai, C. C.; Meshkian, R.; Dahlqvist, M.; Lu, J.; Näslund, L. Å.; Rivin, O.; Caspi, E. N.; Ozeri, O.; Hultman, L.; Eklund, P.; Barsoum, M. W.; Rosen, J., Structural and chemical determination of the new nanolaminated carbide $\mathrm{Mo}_{2} \mathrm{Ga}_{2} \mathrm{C}$ from first principles and materials analysis. Acta Materialia 2015, 99, 157-164.

3. Anasori, B.; Halim, J.; Lu, J.; Voigt, C. A.; Hultman, L.; Barsoum, M. W., Mo $2 \mathrm{TiAlC}_{2}$ : A new ordered layered ternary carbide. Scripta Materialia 2015, 101, 5-7.

4. Anasori, B.; Dahlqvist, M.; Halim, J.; Moon, E. J.; Lu, J.; Hosler, B. C.; Caspi, E. a. N.; May, S. J.; Hultman, L.; Eklund, P.; Rosén, J.; Barsoum, M. W., Experimental and theoretical characterization of ordered MAX phases $\mathrm{Mo}_{2} \mathrm{TiAlC}_{2}$ and $\mathrm{Mo}_{2} \mathrm{Ti}_{2} \mathrm{AlC}_{3}$. Journal of Applied Physics 2015, 118 (9), 094304.

5. Meshkian, R.; Tao, Q.; Dahlqvist, M.; Lu, J.; Hultman, L.; Rosen, J., Theoretical stability and materials synthesis of a chemically ordered MAX phase, $\mathrm{Mo}_{2} \mathrm{ScAlC}_{2}$, and its two-dimensional derivate Mo2ScC2 MXene. Acta Materialia 2017, 125, 476-480.

6. Dahlqvist, M.; Lu, J.; Meshkian, R.; Tao, Q.; Hultman, L.; Rosen, J., Prediction and synthesis of a family of atomic laminate phases with Kagomé-like and in-plane chemical ordering. Science Advances 2017, 3 (7).

7. Tao, Q.; Dahlqvist, M.; Lu, J.; Kota, S.; Meshkian, R.; Halim, J.; Palisaitis, J.; Hultman, L.; Barsoum, M. W.; Persson, P. O. Å.; Rosen, J., Two-dimensional Mo1.33C MXene with divacancy ordering prepared from parent 3D laminate with in-plane chemical ordering. Nature Communications 2017, 8, 14949.

8. Meshkian, R.; Dahlqvist, M.; Lu, J.; Wickman, B.; Halim, J.; Thornberg, J.; Tao, Q.; Li, S.; Intikhab, S.; Snyder, J.; Barsoum, M. W.; Yildizhan, M.; Palisaitis, J.; Hultman, L.; Persson, P. O. A.; Rosen, J., W-Based Atomic Laminates and Their 2D Derivative $\mathrm{W}_{1.33} \mathrm{C}$ MXene with Vacancy Ordering. Adv Mater 2018, 30 (21), e1706409.

9. Sun, Z.; Music, D.; Ahuja, R.; Li, S.; Schneider, J. M., Bonding and classification of nanolayered ternary carbides. Physical Review B 2004, 70 (9), 092102.

10. Sun, Z.; Music, D.; Ahuja, R.; Schneider, J. M., Theoretical investigation of the bonding and elastic properties of nanolayered ternary nitrides. Physical Review B 2005, 71 (19), 193402.

11. Music, D.; Sun, Z.; Ahuja, R.; Schneider, J. M., Coupling in nanolaminated ternary carbides studied by theoretical means: The influence of electronic potential approximations. Physical Review B 2006, 73 (13), 134117.

12. Music, D.; Sun, Z.; Voevodin, A. A.; Schneider, J. M., Electronic structure and shearing in nanolaminated ternary carbides. Solid State Communications 2006, 139 (4), 139-143.

13. Suetin, G. D.; Shein, I. R.; Ivanovskii, A. L., Electronic structure of tungsten aluminum carbides $\mathrm{W}_{2} \mathrm{AlC}$ and $\mathrm{WAlC}_{2}$. Russian Journal of Inorganic Chemistry 2009, 54 (9), 1433-1439.

14. Zhong, Y.; Xia, X.; Shi, F.; Zhan, J.; Tu, J.; Fan, H. J., Transition Metal Carbides and Nitrides in Energy Storage and Conversion. Advanced Science 2016, 3 (5), 1500286.

15. Jochen, M. S.; Zhimei, S.; Denis, M., Theoretical investigation of the bonding and solubility in $\mathrm{Nb}_{2-\mathrm{x}} \mathrm{W}_{\mathrm{x}} \mathrm{AlC}$. Journal of Physics: Condensed Matter 2005, 17 (38), 6047.

16. Dahlqvist, M.; Rosen, J., Order and disorder in quaternary atomic laminates from first-principles calculations. Phys Chem Chem Phys 2015, 17 (47), 31810-21.

17. Tashmetov, M. Y.; Em, V.; Lee, C.; Shim, H.; Choi, Y.; Lee, J., Neutron diffraction study of the ordered structures of nonstoichiometric titanium carbide. Physica B: Condensed Matter 2002, 311 (3), 318-325.

18. Epicier, T.; Dubois, J.; Esnouf, C.; Fantozzi, G.; Convert, P., Neutron powder diffraction studies of transition metal hemicarbides $\mathrm{M}_{2} \mathrm{C}_{1-x}-\mathrm{II}$. In situ high temperature study on $\mathrm{W}_{2} \mathrm{C}_{1-x}$ and $\mathrm{Mo}_{2} \mathrm{C}_{1-x}$. Acta Metallurgica 1988, 36 (8), 1903-1921. 